\title{
Human papilloma virus vaccination: knowledge, awareness and acceptability among medical and paramedical students
}

\author{
Suchith Hoblidar, Suma S. Moni*, Rathnamala M. Desai, Asha Neravi
}

\begin{abstract}
Department of Obstetrics and Gynecology, Sri Dharmasthala Manjunatheshwara College of Medical Sciences and Hospital, Dharwad, Karnataka, India
\end{abstract}

Received: 14 December 2019

Accepted: 21 December 2019

\author{
*Correspondence: \\ Dr. Suma S. Moni, \\ E-mail: suma.moni22@gmail.com
}

Copyright: (c) the author(s), publisher and licensee Medip Academy. This is an open-access article distributed under the terms of the Creative Commons Attribution Non-Commercial License, which permits unrestricted non-commercial use, distribution, and reproduction in any medium, provided the original work is properly cited.

\begin{abstract}
Background: Cervical cancer is the second leading cause of death in india. it is also one of the few malignancies where an infectious etiological agent human papilloma virus (HPV) has been identified. With the advent of HPV vaccination, it is possible to reduce the morbidity and mortality associated with carcinoma cervix. But biggest hurdle to achieve this is the lack of awareness about the availability and use of HPV vaccine. This study was conducted to know knowledge and awareness of HPV infection and vaccination among medical and paramedical students. We also evaluated the acceptability and coverage of HPV vaccine among these students.

Methods: This study was conducted among a total of 520 female students of the Sri Dharmasthala Manjunatheshwara University with the help of a questionnaire. The study group included 207 MBBS students, 167 BDS students, 89 nursing students and 57 physiotherapy students.

Results: Most of the students were in 18-20 years' age group. Nearly $40.57 \%$ of the students knew that HPV is sexually transmitted and $29.80 \%$ were aware that this infection can be prevented. Availability of HPV vaccine was known to $75 \%$ of the students and the main source of their information was through their college teachings. Nearly $43.75 \%$ of the students knew HPV vaccine protects against cervical cancer and $26.73 \%$ of the students were vaccinated. Overall knowledge and awareness were better among medical students.

Conclusions: A lot of work needs to be done so as to make the target population accept HPV vaccine. There is a great difference between awareness of availability of the vaccine and its use. This emphasizes the need for health care professionals to take special interest in promoting this vaccine in the general population.
\end{abstract}

Keywords: Acceptability, Awareness, Carcinoma cervix, Human papilloma virus, Human papilloma virus vaccination, Medical students, Paramedical students, Prevention

\section{INTRODUCTION}

Malignancies are emerging as the second leading cause of death worldwide and globally deaths due to cancer has increased by $17.0 \%$ between 2005 and $2015 .{ }^{1}$ Burden of cancer was 17.5 million cancer cases, 8.7 million deaths, and 208.3 million disability adjusted life years (DALY)s in the year $2015 .^{2}$ Up to 60 per cent of total cancer cases are preventable and nearly $15 \%$ of all cancers are due to infective origin. ${ }^{3}$ Success in prevention of malignances would lead to reduction in morbidity and mortality related to the disease. Awareness regarding the availability of preventive measures remain the missing link in the widespread use of preventive modalities resulting in effective prevention.

India has the highest burden of carcinoma cervix. At an incidence of 22 per 100,000 women per year, it is higher compared to that of the rest of the world being 14 per $100,000 .{ }^{4}$ Cervical cancer is the second leading cause of 
cancer in India and is also the second common cause of death due to cancer among women in India. ${ }^{5}$ Every year $1,34,420$ new cases are detected and causes death among 72,825 women which is predicted to increase to $1,82,027$ and $1,01,362$ by 2020 respectively. ${ }^{6}$ India accounts for $15.2 \%$ of the total cervical cancer deaths in the world. The age standardized rate for DALY was 466 with 428 accounting for years of life lost and 37 years of life lived with disability. ${ }^{5}$ Compared to any other malignancy carcinoma cervix is the leading cause of premature deaths among women in India. ${ }^{5}$

There is a population of 453.02 million of women aged 15 years and above who are at the risk of developing cervical cancer in India. ${ }^{5}$ Indian women have a cumulative lifetime risk of $2.5 \%$ for developing cervical cancer and $1.4 \%$ cumulative lifetime risk of death due to cancer cervix. $^{8}$

Carcinoma cervix is one of the few malignancies where an etiological agent has been identified and also vaccination against the same is available. High risk strain of human papilloma virus (hrHPV) has been identified as the etiological agent. Oncogenic HPV s cause nearly $100 \%$ of cervical cancer. ${ }^{9}$ HPV is one of the most common causes of sexually transmitted diseases. ${ }^{10}$ It has been estimated that more than $80 \%$ of the sexually active women acquire HPV infection by 50 years of age. ${ }^{11}$ The highest prevalence of infection is seen in women soon after the onset of sexual activity. It is found that any given point $5 \%$ of women are found to be infected with HPV. ${ }^{5}$

Among all the serotypes of HPV, 18 serotypes have been identified as the high-risk ones. Of these HPV 16 and 18 are the ones commonly found in carcinoma cervix with HPV 16 being the commonest. Together they contribute to over $70 \%$ of all cervical cancers worldwide. ${ }^{12}$ Studies from India also show the prevalence of HPV among 87.8$96.67 \%$ of women with cervical cancer and 9.9-36.8\% among women with no cancer. ${ }^{13}$ In India HPV 16 was found in $66.7 \%$, HPV 18 in $19.4 \%$, HPV 33 in $5.6 \%$ and HPV 35 in $5.6 \%$ of the cases. Other high-risk types HPV $45,52,58,59$ and 73 was found in less $5 \%$ of the cases. ${ }^{14}$

Vaccination against high risk HPV types play an important role in preventing carcinoma cervix as this is the only medical method available. HPV infection cannot be prevented by any other method except by abstinence and lifetime mutual monogamy. ${ }^{8}$ Also HPV infections are asymptomatic. Genital HPV is ubiquitous with a lifetime risk for HPV infection being 50-80\%. ${ }^{15}$ Natural infections with HPV induces a weak immune response which may not be protective whereas vaccination results in a strong immune response. ${ }^{16}$ Although the impact of vaccination on cancer cervix is awaited, countries which have introduced HPV immunization program have reported reduction in prevalence of vaccine type HPV infections. ${ }^{9}$ Herd immunity and cross-protection are known to augment the impact of vaccine.
India has not yet introduced HPV vaccination in the national immunization program. Vaccination is voluntary and as such depends on the awareness regarding its availability and advantages. Widespread coverage is also hampered by the cost and bias regarding side effects of vaccination.

This study is undertaken to assess the knowledge of HPV infection and vaccination among medical and paramedical students. We have also assessed the acceptability of HPV vaccine among them.

\section{METHODS}

A cross sectional observational study was conducted over a period of 2 months from April 2019 to May 2019. This study was conducted at the colleges affiliated to the Sri Dharmasthala Manjunatheshwara University Sattur Dharwad, Karnataka India. This study was conducted among a total of 207 MBBS students, 167 BDS students, 89 nursing students and 57 physiotherapy students. For the purpose of convenience students were grouped as Group A (MBBS), Group B (BDS), Group C (Nursing) and Group D (Physiotherapy). Inclusion criteria was female students studying medicine, dentistry, nursing and physiotherapy in all academic sessions. Males and postgraduate students were excluded. The study was done using a common questionnaire (Table 1).

Table 1: Questionnaire.

\begin{tabular}{|c|c|}
\hline Age & Education \\
\hline 1.1 & Is HPV infection sexually transmitted? \\
\hline 1.2 & Can HPV infection be prevented? \\
\hline 1.3 & How can the infection be prevented? \\
\hline 1.4 & $\begin{array}{l}\text { What is the risk associated with persistent } \\
\text { HPV infection? }\end{array}$ \\
\hline 2.1 & Do you know about HPV vaccine? \\
\hline 2.2 & What is the source of your information? \\
\hline 2.3 & Against which disease is the vaccine given? \\
\hline 2.4 & $\begin{array}{l}\text { What is the ideal time and age for this } \\
\text { vaccination? }\end{array}$ \\
\hline 2.5 & How many doses are to be given? \\
\hline 3.1 & Have you been vaccinated? \\
\hline 3.2 & If no why? \\
\hline $3 . .3$ & $\begin{array}{l}\text { Do you want to get vaccinated and will you } \\
\text { recommend this vaccine to your family and } \\
\text { friends? }\end{array}$ \\
\hline
\end{tabular}

With this questionnaire information regarding demographic details of the students, their knowledge regarding HPV infection and vaccination were collected. Completed questionnaire was collected back from the students after the allotted time. Ethical approval was obtained from the institution's Human ethical committee. Difference in knowledge among medical and paramedical students was assessed. 


\section{Statistical analysis}

Statistical analysis was done with percentages and compared with chi-square test. A P-value of $<0.05$ was considered significant.

\section{RESULTS}

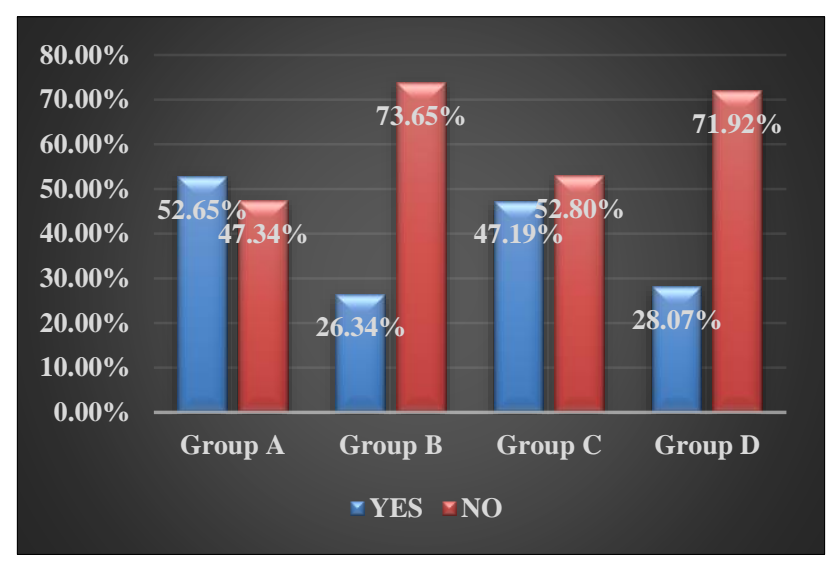

Figure 1: Knowledge if HPV infection sexually transmitted.

A total of 520 students were included in the study, which included 207 MBBS students, 167 BDS students, 89 nursing students and 57 physiotherapy students. Majority of the students $219(42.11 \%)$ belonged to $18-20$ years' age group. There were $214(41.15 \%)$ participants' in $>20$ 22 years' age group and $87(16.73 \%)$ were aged above 22 years.

\section{Knowledge about HPV infection}

\section{Is HPV infection sexually transmitted?}

Nearly half in Group A 109 (52.65\%) knew that HPV infection is sexually transmitted. This was in in contrast with the fact that in all other 3 groups this awareness was less than $50 \%$ (Figure 1). Most of the students 123 (73.65\%) in Group B, 47 (52.80\%) in Group C and 41 (71.92\%) in group D did not know that HPV infections are sexually transmitted. The difference in this knowledge among medical and paramedical students was $109(52.65 \%)$ and $102(32.58 \%)$ respectively. The Pvalue was $<0.00001$ and was statistically significant. Overall awareness was $40.57 \%$.

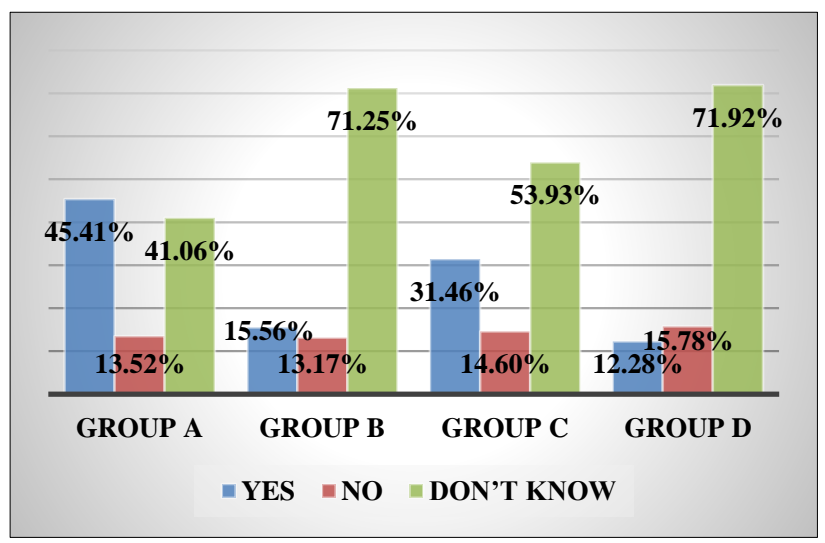

Figure 2: Awareness if HPV infection can be prevented.

Table 2: Methods available for prevention of HPV infection among students who knew HPV infection can be prevented.

\begin{tabular}{|lllll|}
\hline Methods & Group A (94) & Group B (26) & Group C (28) & Group D (7) \\
\hline Vaccination & $39(41.48 \%)$ & $13(50 \%)$ & $15(53.57 \%)$ & $4(57.14 \%)$ \\
\hline Condoms & $13(13.82 \%)$ & $7(26.92 \%)$ & $9(32.14 \%)$ & $3(42.85 \%)$ \\
\hline Avoid multiple sexual partners & $24(25.53 \%)$ & $6(23.07 \%)$ & $3(10.71 \%)$ & 0 \\
\hline Delayed onset of sexual activity & $18(19.14 \%)$ & 0 & $1(3.57 \%)$ & 0 \\
\hline
\end{tabular}

\section{Can HPV infection be prevented?}

In Group A $94(45.41 \%)$ students replied that HPV infection can be prevented, whereas $26(15.56 \%)$ in Group B, $28(31.46 \%)$ in Group C and 7 (12.28\%) in Group D were aware that HPV infections can be prevented (Figure 2). Again, here P-value for difference in knowledge among medical and paramedical students was calculated and the P-value was $<0.00001$ which was statistically significant.

\section{How can the infection be prevented?}

Only $71(13.65 \%)$ of all the students knew that HPV infection can be prevented with vaccination (Table 2).
Students in Group A were better aware about this than students in other 3 groups. Among all the students in each group vaccination as the mode of prevention was known to $39(18.84 \%)$ in Group A, $13(7.78 \%)$ in Group B, 15 $(16.85 \%)$ in Group C and 4 (7.01\%) in Group D.

What is the risk associated with persistent HPV infection?

Persistent HPV infection would lead to carcinoma cervix was replied by $86(41.54 \%)$ Group A students, 28 (16.76\%) students of Group B, 33 (37.07\%) in Group C and $12(21.05 \%)$ in Group D. More than $50 \%$ of students in all the 4 groups did not know that persistence of HPV infection resulted in carcinoma cervix. There were 86 
(41.54\%) medical and $73(23.32 \%)$ paramedical students who were aware that persistent infection would lead to cancer cervix. The P-value here was $<0.00001$ which was statistically significant.

Overall knowledge about HPV infection was better among students in Group A followed by Group C.

\section{Knowledge about HPV vaccination}

Do you know about HPV vaccine?

Majority of students in Group A 176 (85.02\%) and 69 (77.52\%) in Group C were aware of the availability of HPV vaccine. This awareness was slightly lower in Group B $64(38.32 \%)$ and $32(56.14 \%)$ in Group D. The $\mathrm{P}$-value was calculated to be $<0.00001$ which was statistically significant. Overall awareness about the availability of vaccine was $65.57 \%$ (Figure 3).
Group B was lagging in their information about the availability of HPV vaccine. The knowledge in this area among the other 3 groups was above $50 \%$.

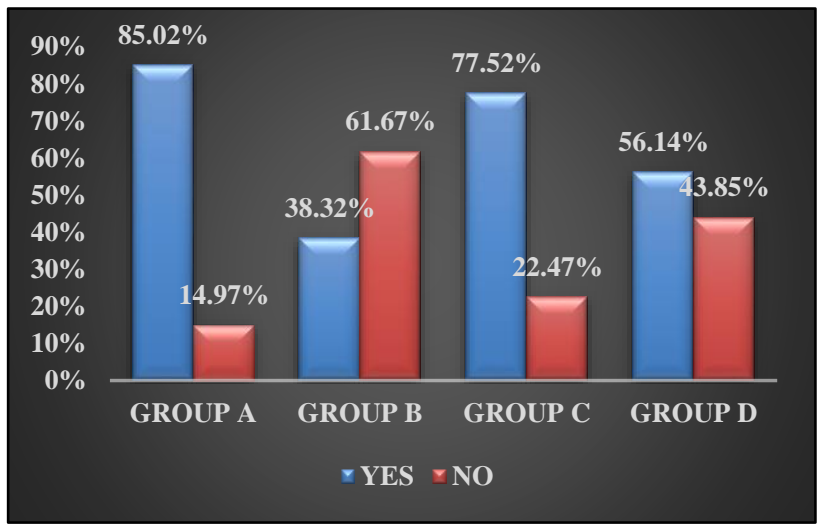

Figure 3: Awareness about the availability of HPV vaccine.

Table 3: Source of Information among students who knew about HPV vaccine.

\begin{tabular}{|lllll|}
\hline Source of information & Group A (176) & Group B (64) & Group C (69) & Group D (32) \\
\hline Professional college books and teachers & $146(82.95 \%)$ & $42(65.62 \%)$ & $58(84.05 \%)$ & $16(50 \%)$ \\
\hline Internet & $18(10.22 \%)$ & $21(32.81 \%)$ & $11(15.94 \%)$ & $14(43.75 \%)$ \\
\hline Newspaper and television & $3(1.7 \%)$ & $1(1.5 \%)$ & 0 & $1(3.12 \%)$ \\
\hline Parents & $7(3.9 \%)$ & 0 & 0 & 0 \\
\hline Friends & $2(1.13 \%)$ & 0 & 0 & $1(3.12 \%)$ \\
\hline
\end{tabular}

Table 4: Against which disease is HPV vaccination given.

\begin{tabular}{|lllll|}
\hline Disease & Group A (207) & Group B (167) & Group C (89) & Group D (57) \\
\hline Carcinoma cervix & $87(42.02 \%)$ & $24(14.37 \%)$ & $28(31.46 \%)$ & $22(38.59 \%)$ \\
\hline HPV infection & $25(12.07 \%)$ & $19(11.37 \%)$ & $16(17.97 \%)$ & $3(5.26 \%)$ \\
\hline Sexually transmitted diseases & $59(28.50 \%)$ & $4(2.3 \%)$ & $19(21.34 \%)$ & $5(8.77 \%)$ \\
\hline Genital warts & 0 & $14(8.38 \%)$ & 0 & 0 \\
\hline Don't know & $36(17.39 \%)$ & $106(633.47 \%)$ & $26(29.21 \%)$ & $27(47.36 \%)$ \\
\hline
\end{tabular}

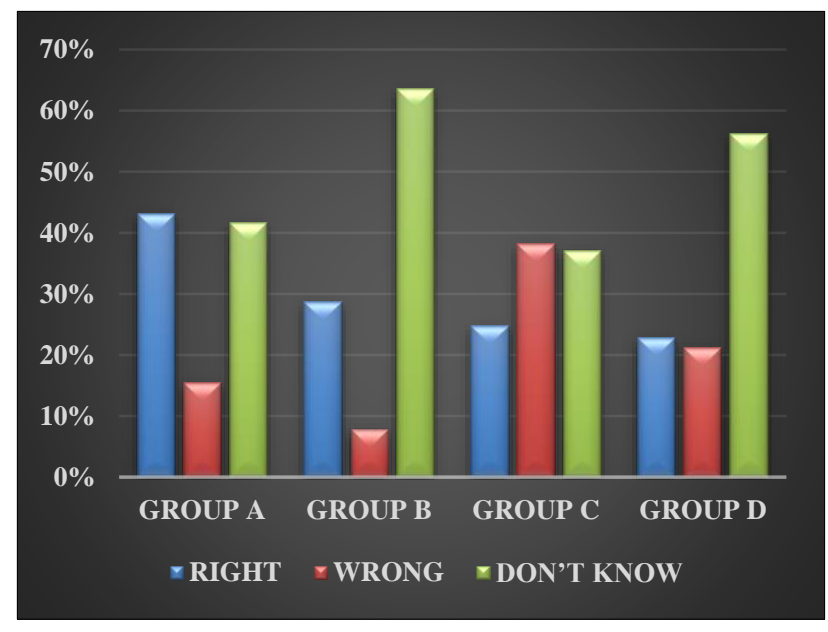

Figure 4: Knowledge about the ideal age for vaccination.
What is the source of your information?

Majority of the students $146(82.95 \%)$ in Group A, $42(65.62 \%)$ in Group B, 58(84.05\%) in Group C and $16(50 \%)$ in Group D came know of this vaccine after learning about it in the college and also from their teachers and clinicians. Internet, newspapers, television, parents and friends were other sources of information (Table 3).

Against which disease is this vaccine is given?

There were $112(54.10 \%)$ students in Group A who replied that the vaccine is given against carcinoma cervix and HPV infections. In Group B $43(25.74 \%)$ students, 44 $(49.94 \%)$ in Group C and $25(43.85 \%)$ in Group D were aware that the vaccine was given against carcinoma cervix and HPV infections. Again, here Group B seems 
to be the least informed group. The P-value for difference among medical and paramedical students was 0.001342 which was statistically significant (Table 3).

What is the ideal time and age at which this vaccine is to be given?

Again, students of Group A were better informed regarding this with $89(42.99 \%)$ of them answering correctly whereas $48(28.74 \%)$ in Group B, $22(24.71 \%)$ in Group C and 13 (22.80\%) in Group D knew the ideal time for the vaccination correctly. Among the students in all the groups who answered correctly only some knew that it has to be given before the onset of sexual activity (Figure 4).

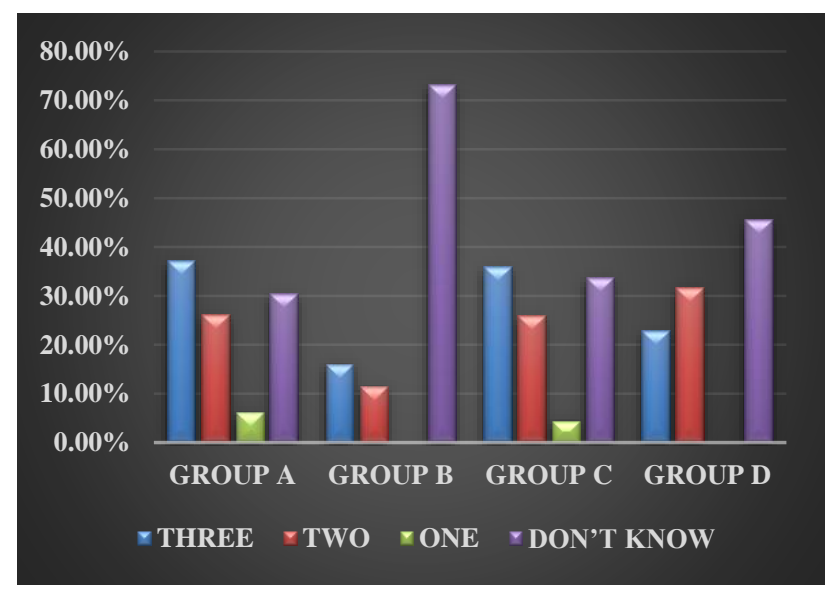

Figure 5: Number of doses of the vaccine required.

How many doses of this vaccine needs to be given?

In Group A 77 (37.19\%) followed by 32 (35.95\%) in Group C knew 3 doses of vaccine is to be given. Only 27 (16.16\%) in Group B and $13(22.80 \%)$ in Group D were aware of the correct dose of the vaccine. All the remaining students didn't know right dose of the vaccine. Awareness was much better in Group A followed by Group C. Group B was least informed among the 4 groups (Figure 5).

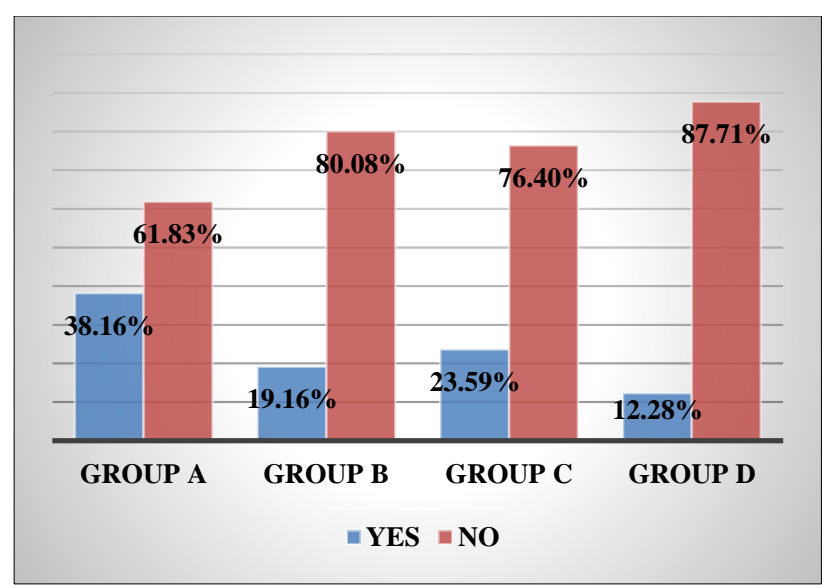

Figure 6: Percentage of students who were vaccinated.

\section{Attitude and acceptability}

Have you been vaccinated?

Overall $139(26.73 \%)$ of the students were vaccinated, the coverage being just above $25 \%$. In Group A 79 (38.16\%) students were vaccinated, followed by Group C $21(23.59 \%)$, Group B $32(19.16 \%)$ and Group D 7 $(12.28 \%)$. There were $79(38.16 \%)$ medical and 60 $(19.16 \%)$ paramedical students who were vaccinated and P-value was $<0.00001$ which was statistically significant (Figure 6).

\section{If not why?}

Lack of awareness about the vaccine was the most important reason for not being vaccinated in 179 $(46.98 \%)$ of all the students. There were $23(17.96 \%)$ students in Group A were not vaccinated as they were sexually inactive. Some other reasons were high cost of the vaccine and was thought to be unnecessary. Some students responded that they were not recommended to be vaccinated (Table 5).

Table 5: Reasons for not being vaccinated.

\begin{tabular}{|lllll|}
\hline Reasons & Group A (128) & Group B (135) & Group C (68) & Group D (50) \\
\hline Lack of awareness & $31(24.21 \%)$ & $103(77.77 \%)$ & $20(29.41 \%)$ & $25(50 \%)$ \\
\hline Not sexually active & $23(17.96 \%)$ & $5(3.7 \%)$ & $2(2.94 \%)$ & 0 \\
\hline Unnecessary & $18(14.06 \%)$ & $12(8.88 \%)$ & $2(2.94 \%)$ & $4(8 \%)$ \\
\hline Not recommended & $25(19.53 \%)$ & 0 & $8(11.76 \%)$ & 2 \\
\hline Expensive & $2(1.56 \%)$ & 0 & 0 & 0 \\
\hline No reason & $29(22.65 \%)$ & $15(11.11 \%)$ & $36(52.94 \%)$ & $19(38 \%)$ \\
\hline
\end{tabular}

Will you get vaccinated and will you recommend this vaccine to your friends and family?
All the students in all the groups wanted to be vaccinated. All students replied that they would recommend this vaccine to their family and friends. 


\section{DISCUSSION}

This study was aimed at knowing the awareness and acceptability of HPV vaccination among female students in medical and various paramedical courses. HPV vaccination and routine screening with pap smear has been documented to have a great potential in reducing the incidence of carcinoma cervix there by reducing the economic and health burden to the society. Many developed countries have been able to achieve almost complete coverage. In India carcinoma cervix still continues to be a major health problem as screening is not universal and awareness about the same is limited. Despite the HPV vaccine being available since long the uptake of HPV vaccine among the Indian population is low. This is a major concern as missing out on vaccination would mean a great opportunity for preventing cancer cervix is being lost. The potential of the vaccine to prevent HPV infection is maximum when it is given before onset of sexual activity. It has been estimated that if $70 \%$ of Indian target population (adolescent girls) are vaccinated there will be more than $50 \%$ reduction in mean lifetime risk for cancer. ${ }^{17}$ It has also been found to be cost effective when DALY s averted were calculated and also in a modeled scenario has been shown to prevent 2 million future deaths among women vaccinated in their adolescence. ${ }^{17}$ It has been found that female-only vaccination is cost effective when compared with Pap smear screening in preventing precancerous lesions and cervical cancer. ${ }^{18}$ In India where the infrastructure for Pap smear screening is not well-developed vaccination would be ideal choice as it can be incorporated with the rest of the immunization schedule.

HPV vaccination protects against cervical pre cancer in adolescent girls and women between 15-26 years of age. There is reduction in CIN2+, CIN3+ and AIS. This protection is higher in individuals who are negative for hrHPV and HPV. ${ }^{16,18}$ Vaccination in women between 25 45 years, the effect on pre cancer is smaller, as they would be already exposed to HPV and vaccination wouldn't clear the infection. ${ }^{19}$

With the present study we found that the overall awareness of HPV infection was better among medical students and most important source of information was medical college teaching. Nearly $40.57 \%$ of the students knew that it is a sexually transmitted infection in comparison with the study by Sumita et al where $38 \%$ of the students responded that HPV is sexually transmitted. ${ }^{20}$ But this finding was in contrast to the study by Idowu et al where this awareness was $78.4 \%$ and study by Das $\mathrm{N}$ et al also found that $91.5 \%$ of the respondents knew that HPV was sexually transmitted. ${ }^{21,22}$ Persistent HPV as a cause for carcinoma cervix was known to $30.57 \%$ of the students. A study by Pandey et al found that $89.2 \%$ of the students knew that HPV infection was the etiological agent for carcinoma cervix. ${ }^{23}$
Availability of HPV vaccine was known to $65.57 \%$ of the students. A study by Das $\mathrm{N}$ et al found that $75 \%$ of the students knew about the availability of vaccine. ${ }^{22}$ The present study found that $30.96 \%$ of the students knew that this vaccine is given against carcinoma cervix. A study by Swarnapriya $\mathrm{K}$ et al showed that $60.1 \%$ of the respondents knew that HPV vaccine protects against cervical cancer. $^{24}$

In the present study $26.73 \%$ of the students were vaccinated. This was higher when compared with studies by Sarnapriya et al and Sunite GA et al where vaccination coverage was $6.8 \%$ and $5.5 \%$ respectively. ${ }^{24,25}$ In the present study $73.26 \%$ of the students were not vaccinated and the chief reason for which was lack of awareness in $46.98 \%$ of the students. This finding is similar to the studies done by Sunite et al. ${ }^{25}$ In the study done by Nivedita et al high cost of the vaccine was the reason for not being vaccinated. ${ }^{22}$ All the students who were not vaccinated were willing to get vaccinated in the present and they were also willing to recommend it to their family and friends in the present study. In the study done by Swarnapriya et al $48.54 \%$ of the participants were not keen on getting vaccinated. ${ }^{24}$ Nivedita et al reported that $83 \%$ of respondents were willing to get vaccinated but $9 \%$ felt that vaccination would lead to promiscuity. ${ }^{22}$

The finding of the present study was contrasting with studies done in some of the developing countries where nearly $67 \%$ were vaccinated and $95 \%$ of women and $80 \%$ of men were aware that it was against cervical cancer. ${ }^{26}$ In the present only $30.96 \%$ were aware that this vaccine is protective against cervical cancer.

The limitation of this study is that the study population are students associated with medical field. As was noted it was found that the main source of information for these students were their study materials and it's obvious that their knowledge would be better than the general population. Systematic review by Thulaseedharan et al highlights this striking reduction in knowledge in the general population where the awareness about pap smear was 3.5-9.7\% and majority were unaware about HPV vaccine. $^{27} \mathrm{~A}$ study by Madhivanan $\mathrm{P}$ et al parents of adolescents had very poor knowledge about HPV and its relation to cervical cancer. ${ }^{28} \mathrm{~A}$ systematic analysis found that $13-75 \%$ of the parents were willing to vaccinate their daughters. ${ }^{27}$

As noted from this study there is a difference in the awareness of the availability of HPV vaccine and its coverage. Nearly $43.75 \%$ of the students knew that this vaccine is protective against cervical carcinoma but only $26.73 \%$ of them were vaccinated. This shows that there is lack of encouragement and guidance to be vaccinated. They have just gained knowledge from their books and classroom teaching but have some inhibitions in being vaccinated. But the most promising finding from this study was that all the students were willing to get vaccinated after the study. We have distributed 
information leaflets after collecting the questionnaire from the students. This was aimed at improving their knowledge of HPV infection and uses of HPV vaccination.

The main goal in achieving high vaccine coverage is to educate the parents of the adolescent students who are attending primary and high school about the vaccine. This is the age where vaccination gives maximum protection, before their sexual debut.

A study by Hussain $\mathrm{S}$ et al showed that $15 \%$ of students knew about cervical carcinoma among whom $73 \%$ knew it was due to HPV infection. In the same study it was also noted that only $13 \%$ of parents were willing to vaccinate their children but $63.6 \%$ of students were willing to be vaccinated. This study involved students less than 18 years also. ${ }^{29}$ This was in contrast with the findings by Jessica et al where $79 \%$ of the parents and $82 \%$ of physicians were willing to vaccinate. ${ }^{30}$

Another study from Netherlands by Lenselink et al, showed that $29.5 \%$ had ever heard of HPV, and $14.3 \%$ parents knew HPV is related to cervical cancer and $87.9 \%$ were willing to vaccinate their children. ${ }^{31}$ In a study done by Saha et al among students of 4 women's colleges in Kolkata it was noted that awareness about cancer cervix was very low and only $15 \%$ of them were familiar with cancer cervix. ${ }^{32}$

Indian parents are less interested in vaccinating their children and hence the vaccine coverage in the target population is not up to the required level. There are various prejudices against vaccination among the parents. Common barriers as reported by Paul $\mathrm{P}$ et al were side effects, vaccine cost, and missing work to receive vaccine. Parents were strongly influenced by healthcare providers' recommendations. ${ }^{33}$ Periodic reinforcement of awareness in the form health camps by health care professionals among school students and their parents would improve the vaccine uptake. The aim should be that at least all girls are vaccinated before their sexual debut.

\section{CONCLUSION}

There is large gap to be filled in order to improve the awareness about HPV vaccination. Research in field of disease prevention has armed us with the potential of being able to eradicate carcinoma cervix. But this requires that every child needs to be vaccinated and every mother needs to be screened. The onus of this lies with the health care providers to be able motivate the eligible clients for vaccination and screening.

\section{Funding: No funding sources} Conflict of interest: None declared

Ethical approval: The study was approved by the Institutional Ethics Committee

\section{REFERENCES}

1. Wang H, Naghavi M, Allen C, Barber RM, Bhutta ZA, Carter A, et al. Global, regional, and national life expectancy, all-cause mortality, and causespecific mortality for 249 causes of death, 19802015: a systematic analysis for the Global Burden of Disease Study 2015. Lancet. 2016;388(10053):1459544.

2. Fitzmaurice C, Allen C, Barber RM, Barregard L, Bhutta ZA, Brenner H, et al. Global, regional, and national cancer incidence, mortality, years of life lost, years lived with disability, and disabilityadjusted life-years for 32 cancer groups, 1990 to 2015: a systematic analysis for the global burden of disease study. JAMA Oncol. 2017;3(4):524-48.

3. Mehrotra R, Kaushik R. A stitch in time saves nine: Answer to the cancer burden in India. Indian $\mathrm{J}$ Med Res. 2018;147(2):121-4.

4. Mehrotra R, Hariprasad R, Rajaraman P, Mahajan V, Grover R, Kaur P, et al. Stemming the wave of cervical cancer: human papillomavirus vaccine introduction in India. J Glob Oncol. 2018;4:1-4.

5. ICO/IARC Information Centre on HPV and Cancer. Human Papillomavirus and Related Cancers India, Fact Sheet; 2018.

6. Ferlay J, Shin HR, Bray F, Forman D, Mathers C, Parkin DM. GLOBOCAN 2008 vl.2, Cancer Incidence and Mortality Worldwide: IARC Cancer Base No 10. Lyon, France: International Agency for Research on Cancer; 2010. Available at: http://globocan.iarc.fr.

7. Ferlay J, Shin HR, Bray F, Forman D, Mathers C, Parkin DM. Estimates of worldwide burden of cancer in 2008: GLOBOCAN 2008. Int J Cancer. 2010;127:2893-917.

8. Kaarthigeyan K. Cervical cancer in India and HPV vaccination. Indian $\mathrm{J}$ Med Paediatr Oncol. 2012;33(1):7-12.

9. Lee LY, Garland SM. Human papillomavirus vaccination: the population impact. F1000Res. 2017;6:866.

10. World Health Organization. Weekly Epidemiol Record. 2017;92:241-68.

11. Singh N. HPV and Cervical cancer - prospects for prevention through vaccination. Indian $\mathrm{J}$ Med Paediatr Oncol. 2005;26:20-3.

12. World Health Organization: Media Centre: Human Papillomavirus (HPV) and cervical cancer; 2016.

13. Sreedevi A, Javed R, Dinesh A. Epidemiology of cervical cancer with special focus on India. Int $\mathbf{J}$ Womens Health. 2015;7:405-14.

14. Bansal A, Singh MP, Rai B. Human papillomavirusassociated cancers: A growing global problem. Int $\mathbf{J}$ Appl Basic Med Res. 2016;6(2):84-9.

15. Myers ER, McCrory DC, Nanda K, Bastian L, Matchar DB. Mathematical model for the natural history of human papillomavirus infection and cervical carcinogenesis. Am J Epidemiol. 2000;151:1158-71. 
16. Rathi A, Garg S, Meena GS. Human papilloma virus vaccine in indian settings: need of the hour. J Vaccines Vaccin. 2016;7:346.

17. Goldie SJ, O'Shea M, Campos NG, Diaz M, Sweet S, Kim SY. Health and economic outcomes of HPV 16,18 vaccination in 72 GAVI-eligible countries. Vaccine. 2008;26:4080-93.

18. Marra F, Cloutier K, Oteng B, Marra C, Ogilvie G. Effectiveness and cost effectiveness of human papillomavirus vaccine: a systematic review. Pharmaco. 2009;27:127-47.

19. Arbyn M, Xu L, Simoens C, Martin-Hirsch PP. Prophylactic vaccination against human papillomaviruses to prevent cervical cancer and its precursors. Cochrane Database Syst Rev. 2018;5(5):CD009069.

20. Mehta S, Rajaram S, Goel G, Goel N. Awareness about human papilloma virus and its vaccine among medical students. Indian $\mathbf{J}$ Community Med. 2013;38(2):92-4.

21. Idowu A, Olowookere SA, Israel OK, Akinwumi AF. Human papillomavirus vaccine acceptability and uptake among medical and paramedical students of a Nigerian Tertiary Health Institution. Am J Pub Health Res. 2019;7(4):143-50.

22. Niveditha Das E, Francis PT. HPV vaccine knowledge and coverage among female students in a medical college, Kerala. Int J Community Med Public Health. 2018;5:5133-8.

23. Pandey D, Vanya V, Bhagat S, Vs B, Shetty J. Awareness and attitude towards human papillomavirus (HPV) vaccine among medical students in a premier medical school in India. PLoS One. 2012;7(7):e40619.

24. Swarnapriya K, Kavitha D, Reddy GMM. Knowledge, attitude and practices regarding hpv vaccination among medical and para medical in students, india a cross sectional study. Asian Pacific J Cancer Prevent. 2015;16(18):8473-7.

25. Ganju SA, Gautam N, Barwal V, Walia S, Ganju S. Assessment of knowledge and attitude of medical and nursing students towards screening for cervical carcinoma and HPV vaccination in a tertiary care teaching hospital. Int J Community Med Public Health. 2017;4:4186-93.
26. Blödt S, Holmberg C, Müller-Nordhorn J, Rieckmann N. Human papillomavirus awareness, knowledge and vaccine acceptance: a survey among 18-25year old male and female vocational school students in Berlin, Germany. Eur J Public Health. 2012;22(6):808-13.

27. Thulaseedharan JV, Frie KG, Sankaranarayanan R. Challenges of health promotion and education strategies to prevent cervical cancer in India: A systematic review. J Edu Health Promot. 2019;8:216.

28. Madhivanan P, Krupp K, Yashodha MN, Marlow L, Klausner JD, Reingold AL. Attitudes toward HPV vaccination among parents of adolescent girls in Mysore, India. Vaccine. 2009;27:5203-8.

29. Hussain S, Nasare V, Kumari M, Sharma S, Khan MA, Das BC, et al. Perception of human papillomavirus infection, cervical cancer and HPV vaccination in North Indian population. PLoS One. 2014;9(11):e112861.

30. Barnack JL, Reddy DM, Swain C. Predictors of parents' willingness to vaccinate for Human Papilloma Virus and Physicians' intentions to recommend the vaccine. Women's Health. 2010;20:28-34

31. Lenselink $\mathrm{CH}$, Gerrits MMJG, Melchers WJG, Massuger LFAG, Hamont D, Bekkers RLM. Parental acceptance of human papillomavirus vaccines. Eu J Obstet Gynecol Repro Biol. 2008;137:103-7.

32. Saha A, Chaudhury AN, Bhowmik P, Chatterjee R. Awareness of cervical cancer among female students of premier colleges in Kolkata, India. Asian Pac J Cancer P. 2010;11(4):1085-90.

33. Paul P, Tanner AE, Gravitt PE, Vijayaraghavan K, Shah KV, Zimet GD, et al. Acceptability of HPV vaccine implementation among parents in India. Health Care Women Int. 2014;35(10):1148-61.

Cite this article as: Hoblidar S, Moni SS, Desai RM, Neravi A. Human papilloma virus vaccination: knowledge, awareness and acceptability among medical and paramedical students. Int J Reprod Contracept Obstet Gynecol 2020;9:474-81. 